\title{
Efficacy of Dilute Povidone-Iodine against Multi- Drug Resistant Bacterial Biofilms, Fungal Biofilms and Fungal Spores
}

\author{
Capriotti $\mathrm{K}^{1,3^{*}}$, Pelletier $\mathrm{J}^{2,3}$, Barone $\mathrm{S}^{3}$ and Capriotti $\mathrm{J}^{2,3}$ \\ ${ }^{1}$ Bryn Mawr Skin and Cancer Institute, 919 Conestoga Road, Building 2, Suite 106, Rosemont, PA 19010, USA
}

${ }^{2}$ Plessen Ophthalmology, 3006 Orange Grove, Christiansted, USVI 00820, USA

${ }^{3}$ Veloce BioPharma, LLC, 1007 N. Federal Hwy \#E4, Fort Lauderdale, FL 33304, USA

Received: January 29, 2018; Accepted: February 05, 2018 ; Published: February 11, 2018

*Corresponding author: Kara Capriotti, MD, Veloce BioPharma, LLC, 1007 N. Federal Hwy \#E4, Fort Lauderdale, FL 33304, USA, Tel: (267) 4567956; E-mail: kcapriotti@velocebiopharma.com

\section{Abstract \\ Objective: To study the in vitro effect of novel low-dose povidone- iodine formulations against established biofilms of multi-drug resistant Staphylococcus aureus, Klebsiella pneumoniae, Pseudomonas aeruginosa and Candida albicans and to test the Minimal Inhibitory Concentration of the same formulations against Candida auris, Trichophton mentagrophytes, Microsporum canis, Candida albicans and Aspergillus fumigatus.}

Methods: Biofilms of multi-drug resistant Staphylococcus aureus, Klebsiella pneumoniae, Pseudomonas aeruginosa and Candida albicans were developed on solid surfaces using the Calgary Biofilm Device plate. Minimum biofilm eradication concentration was then determined for each test drug and for control samples of known antimicrobials, ciprofloxacin and itraconazole. Quality control fungal strains of Candida auris, Trichophton mentagrophytes, Microsporum canis, Candida albicans and Aspergillus fumigatus were grown on Sabouraud's Dextrose Agar plates as the growth medium for the anti-fungal susceptibility. Minimal Inhibitory Concentration was then determined for each test drug and for control samples of know antifungals, fluconazole and amphotericin B.

Results: The low-dose povidone-iodine formulations completely eliminated all biofilms of bacterial and fungal species in the test systems. Ciprofloxacin was able to eradicate one bacterial biofilm only at concentrations greater than $0.25 \mathrm{ug} / \mathrm{mL}$. Fluconazole was ineffective against $C$. albicans, $A$. fumigatus and $C$. auris. Amphotericin $B$ had good anti-fungal activity against fungal strains.

Conclusions: These novel dilute PVP-I formulations are effective anti-biofilm and anti-fungal /sporicidal agents in vitro. Further evaluation in living models is warranted.

Keywords: Biofilm; Povidone-Iodine; Wounds;

\section{Introduction}

Biofilms are pathogen agglomerations attached to a surface and embedded in an extracellular matrix [1]. Formation of biofilm is a successful strategy that protects the bacteria, fungi and yeasts from environmental danger, antimicrobial peptides, antibiotics and phagocytosis enabling a state of chronic persistence in the host.
Biofilms are not just bacterial slime layers but rather represent complex biological systems. The comprising microorganisms are organized into a coordinated functional community. Biofilms are often attached to a surface and may include a single species or a diverse group of sessile microorganisms. These specialized heterogeneous communities are strengthened and protected by the biofilm in a manner that eventually leads to downstream deleterious gene expression and the manifestation of pathogenic factors. Chronic wounds have been shown to involve biofilm formation of both bacterial and fungal species [2,3]. It is in such a setting that biofilm microorganisms are able to share nutrients and are sheltered from harmful factors in the environment, such as desiccation, antibiotics, and the body's immune system $[4,5]$.

More recently it has been noted that bacterial biofilms may impair cutaneous wound healing and reduce topical antibacterial efficiency in healing or treating infected skin wounds [6]. Chronic wounds are often a result of cutaneous surgery, vascular insufficiency or trauma, frequently requiring management by primary care physicians, dermatologists, plastic surgeons and wound care specialists. During normal wound healing, the process that leads to tissue regeneration results from a series of tightly regulated sequential events $[7,8]$. In the case of chronic, non-healing wounds, this process is disrupted, leading to a prolonged inflammatory response and stalled healing. It is hypothesized that microbial colonization and the formation of a biofilm within the wound bed is positively associated with the transition from the acute to chronic state even without classical signs of infection [9]. When a biofilm forms, the penetration of some antimicrobials is reduced, while some individual members shift their metabolism to a more dormant state that can render other antibiotics ineffective. Treatment strategies are further complicated by co-morbidities that affect circulation such as diabetes, poor perfusion, and malnutrition, increasing the risk of infection and reducing the success of orally administered antibiotics [9]. It follows therefore, that early detection of biofilms in wounds is crucial to successful chronic wound management. 
Many of the treatments currently available are designed to treat acute wound infections, which, unlike chronic infections, tend to appear quickly and run their course over a short period of time. Planktonic bacteria typically respond to antibiotics and are easily exterminated by a healthy immune system. In contrast, chronic wounds are normally characterized by a tenacious and excessive inflammatory response when compared with acute wounds and are less susceptible to antibiotics [10]. Hence, the lack of antimicrobial effectiveness may be related to reduced or incomplete penetration of antimicrobials into the biofilm. A novel approach to the aforementioned problem is presented that employs the common antiseptic povidone-iodine at very low concentrations in a gel formulation to chronic wounds. Similar formulations have already been successfully used for indications for dermatology and ophthalmology [11,12]. An in vitro assay was performed to further characterize the anti-biofilm effect of this clinically successful treatment against organisms known to form biofilms in cutaneous wound infections.

\section{Materials and Methods}

\section{Preparation of PVP-I Formulation}

The test formulations for biofilms consist of povidone-iodine at or below $2 \%(\mathrm{w} / \mathrm{w})$ in solvent systems that can be tailored to form solutions or cellulosic gels incorporating dimethylsulfoxide as a co-solvent. These dilute povidone-iodine systems allow the preparation and room-temperature stabilization of povidoneiodine concentrations from $1 \%$ to as low as $0.15 \%$ in solutions and gel systems. For these experiments povidone-iodine solutions were prepared at $2 \%(\mathrm{w} / \mathrm{w})$ and povidone-iodine gels were prepared at $0.25 \%(\mathrm{w} / \mathrm{w})$. Subsequent dilutions were prepared of the solutions and gels to achieve lower concentration solutions for evaluation.

\section{Challenge Bacterial Organism Preparation}

Test organisms were obtained from the American Type Culture Collection (Manassas, VA) or Eurofins Medinet, Inc. (Herndon, VA) (Table 1). The strains were maintained as a frozen glycerol stocks at $-80^{\circ} \mathrm{C}$. The bacterial strains or C. albicans were prepared by thawing a glycerol stock, streaking and growing onto Tryptic Soy Agar (TSA) or Sabouraud's Dextrose Agar (SDA) plates, respectively and incubating overnight at $35 \pm 2^{\circ} \mathrm{C}$ in aerobic conditions and then used for the assay. The completely synthetic medium RPMI-1640 (with glutamine, without bicarbonate, and with phenol red as a pH indicator) was buffered with $0.165 \mathrm{~mol} / \mathrm{L}$. MOPS (3-[N-morpholino] propanesulfonic acid) buffer was used as the growth medium for the fungal strain in the MBEC assay.

\section{Challenge Fungal Organism Preparation}

The fungal strains were obtained from the American Type Culture Collection (Manassas, VA), and Center for Disease Control and Prevention (CDC) (Atlanta, GA) (Table 1). The strains were maintained as a frozen glycerol stocks at $-80^{\circ} \mathrm{C}$. The fungal strains were prepared by thawing a glycerol stock, streaking and growing onto Sabouraud's Dextrose Agar (SDA) plates with an overnight incubation at $27-30 \pm 2{ }^{\circ} \mathrm{C}$ in aerobic conditions and then used for the assay. The completely synthetic medium RPMI1640 (with glutamine, without bicarbonate, and with phenol red as a pH indicator) was buffered with $0.165 \mathrm{~mol} / \mathrm{L}$ MOPS (3-[N-morpholino] propanesulfonic acid) to obtain a $\mathrm{pH}$ of 6.9 7.1 at room temperature and was used as the growth medium for the anti-fungal susceptibility MIC assay.

\begin{tabular}{|c|c|c|c|c|}
\hline$\#$ & Organism & Isolate \# & Phenotype & Source \\
\hline 1 & $\begin{array}{l}\text { Staphylococcus } \\
\text { aureus }\end{array}$ & $\begin{array}{r}\text { ATCC } \\
33591\end{array}$ & $\begin{array}{l}\text { Multi-drug } \\
\text { resistant }\end{array}$ & ATCC \\
\hline 2 & $\begin{array}{l}\text { Klebsiella } \\
\text { pneumoniae }\end{array}$ & $\begin{array}{l}\text { ATCC BAA- } \\
2473^{\mathrm{TM}}\end{array}$ & $\begin{array}{l}\text { Multi-drug } \\
\text { resistant }\end{array}$ & ATCC \\
\hline 3 & $\begin{array}{c}\text { Pseudomonas } \\
\text { aeruginosa }\end{array}$ & 1674623 & $\begin{array}{l}\text { Multi-drug } \\
\text { resistant }\end{array}$ & Eurofins \\
\hline 4 & Candida albicans* & 3288194 & $\begin{array}{l}\text { Multi-drug } \\
\text { resistant }\end{array}$ & Eurofins \\
\hline 5 & Candida auris & CDC 0389 & $\begin{array}{l}\text { Multi-drug } \\
\text { resistant }\end{array}$ & ATCC \\
\hline 6 & $\begin{array}{l}\text { Trichophton } \\
\text { mentagrophytes }\end{array}$ & MYA4439 & $\begin{array}{l}\text { Quality } \\
\text { Control }\end{array}$ & ATCC \\
\hline 7 & Microsporum canis & $\begin{array}{l}\text { ATCC } \\
26299\end{array}$ & $\begin{array}{l}\text { Quality } \\
\text { Control }\end{array}$ & ATCC \\
\hline 8 & Candida albicans** & $\begin{array}{l}\text { ATCC } \\
90028\end{array}$ & $\begin{array}{l}\text { Quality } \\
\text { Control }\end{array}$ & ATCC \\
\hline 9 & $\begin{array}{l}\text { Aspergillus } \\
\text { fumigatus }\end{array}$ & MYA3626 & $\begin{array}{l}\text { Quality } \\
\text { Control }\end{array}$ & ATCC \\
\hline \multicolumn{5}{|c|}{$\begin{array}{l}\text { *Strain tested for Minimum Biofilm Eradication Concentration } \\
\text { **Strain tested for Minimal Inhibitory Concentration }\end{array}$} \\
\hline
\end{tabular}

\section{Comparator antimicrobials and controls}

Minimum Biofilm Eradication Concentration (MBEC) for bacteria was measured using ciprofloxacin (Cat \# 17850, Lot \# 456829, Potency $98.0 \mu \mathrm{g} / \mathrm{mL}$ ) and itraconazole (Cat \# I6657, Lot \# 087K1322) were obtained from Sigma (St. Louis, MO, USA). Antibiotic stocks were prepared in appropriate solvents following the CLSI guidelines [13].

\section{Comparator antifungals and controls}

Minimal Inhibitory Concentration (MIC) for fungi was measured using amphotericin B (Cat \# A9528-100 mg, Lot \# 076M4136V) and fluconazole (F8929-100 mg, Lot \# 036MA709V) were obtained from Sigma (St. Louis, MO, USA). Antifungal stocks were prepared in appropriate solvents following the CLSI guidelines $[13,14]$.

\section{Minimum Biofilm Eradication Concentration}

Minimum biofilm eradication concentration values provide estimates on the concentration of an antimicrobial product required to kill/disrupt the bacterial biofilm. The Calgary Biofilm Device (CBD) plate allows for biofilm formation on a lid containing 96 pegs. The inoculum was diluted to $1 \times 10^{7} \mathrm{CFU} / \mathrm{mL}$ in Tryptic Soy Broth (TSB) for bacterial strains and RPMI media 
for C. albicans before inoculating the CBD plate. The CBD plate was incubated with test microorganism for 24 hours at $35^{\circ} \mathrm{C}$ on a shaker at $150 \mathrm{rpm}$. The MBEC assay was conducted as described in Ceri, et al [15].

\section{Biofilm Eradication Assay}

A treatment plate was made with the three test articles and comparator antibiotics. The $0.25 \%$ PVP-I gel test article was highly viscous; hence only one concentration (full strength at 100\%) was tested. Two percent (w/w) PVP-I solutions were serially diluted 2 -fold and the resulting diluted test articles were tested down to $0.00018 \%(\mathrm{v} / \mathrm{v})$. Ciprofloxacin and itraconazole were used as positive controls for bacterial strains and C. albicans, respectively. Ciprofloxacin was tested at the following concentrations $(\mu \mathrm{g} /$ $\mathrm{mL}): 128,64,32,16,8,4,2,1,0.5,0.25,0.125$ and $0.0625 \mu \mathrm{g} / \mathrm{mL}$. Itraconazole was tested at the following concentrations $(\mu \mathrm{g} / \mathrm{mL})$ : $1024,512,256,128,64,32,16,8,4,2,1$ and $0.5 \mu \mathrm{g} / \mathrm{mL}$.

The cation-adjusted Mueller Hinton Broth (CAMHB)/ RPMI (for $C$. albicans) were used as negative control. The CBD plate with the pegs containing a robust biofilm was first rinsed in PBS and then transferred to the treatment plate containing the test articles and control. The plate was incubated for 24 hours at $35^{\circ} \mathrm{C}$ and then read for determination of MIC values. After incubation, the pegs were rinsed in PBS twice and transferred to a recovery plate containing fresh culture media. The pegs were sonicated in a water bath sonicator for 30 minutes to detach any remaining adherent biofilm. The plate was incubated overnight at $35^{\circ} \mathrm{C}$ to evaluate growth and the MBEC values were determined.

\section{Anti-fungal Susceptibility Minimal Inhibitory Concentration (MIC) Testing}

Each MIC assay included eleven 2-fold serial dilutions of the antifungal agents. Test concentrations for the test article were tested at the following concentrations: $50 \%, 25 \%, 12.5 \%$, $6.250 \%, 3.125 \%, 1.563 \%, 0.781 \%, 0.391 \%, 0.195 \%, 0.098 \%$ and $0.049 \% \mathrm{v} / \mathrm{v}$. Amphotericin B and Fluconazole were tested at 64, $32,16,8,4,2,1,0.5,0.25,0.125$ and $0.0625 \mu \mathrm{g} / \mathrm{mL}$.

MIC - Broth microdilution assays were performed according to the procedures detailed in CLSI document M38-A2 and document M27-A3 [1 - 2]. Briefly, 2X stock solutions of test articles were prepared at $128 \mu \mathrm{g} / \mathrm{mL}$ for Amphotericin B and Fluconazole. Two-fold serial dilutions of the stock solutions were performed. Diluted stock solutions of the fungal spores were adjusted (to be equivalent to $8 \times 10^{4} \mathrm{CFU} / \mathrm{mL}$ ). 1X final concentration of the antifungals or antibiotics was obtained when they were combined with the fungal spore broth in the microtiter plate. The final concentration of the fungal spores in the microtiter plate was $4 \times 10^{4} \mathrm{CFU} / \mathrm{mL}$. Plates were incubated for 7 days at $30 \pm 2^{\circ} \mathrm{C}$ for $M$. canis and $48 \mathrm{~h}$ at $27-30^{\circ} \mathrm{C}$ for all the other strains in an ambient air incubator. MIC values recorded are the minimum concentration of the test articles that inhibited the visible growth as observed by unaided eye. The MIC values were expressed in $\mathrm{v} / \mathrm{v} \%$ for the test article and in $\mu \mathrm{g} / \mathrm{mL}$ for the control antibiotics (Table 2). The assay was performed in duplicates.

Table 2: MBEC assay results

\begin{tabular}{|c|c|c|c|c|c|c|}
\hline \multirow{2}{*}{ Strains } & \multirow{2}{*}{ Isolate ID } & \multirow{2}{*}{ Phenotype } & \multicolumn{4}{|c|}{ MBEC (\% PVP-I and $\mu \mathrm{g} / \mathrm{mL}$ Abx) } \\
\hline & & & 1\% PVP-I Solution & $0.25 \%$ PVP-I Gel & Ciprofloxacin & Itraconazole \\
\hline S. aureus & ATCC 33591 & MDR & 25 & 100 & 0.25 & NA \\
\hline K. pneumoniae & BAA-2473 & MDR & 25 & 100 & $>128$ & NA \\
\hline P. aeruginosa & 1674623 & MDR & 25 & 100 & $>128$ & NA \\
\hline C. albicans & 3288194 & MDR & 25 & 100 & NA & $>1024$ \\
\hline
\end{tabular}

\section{Results}

MBEC assay was carried to determine if the low-dose PVP-I test articles can disrupt a pre-existing robust biofilm of the microorganisms that were grown on the pegs for 24 hours. PVP-I solutions at concentration as low as $0.25 \%(\mathrm{w} / \mathrm{w})$ and PVP-I gel at $0.25 \%(\mathrm{w} / \mathrm{w})$ completely eradicated the biofilms of all the test microorganisms (Table 2). Comparator antibiotics were ineffective in eradicating biofilms of test microorganism except ciprofloxacin which had a MBEC value of $0.25 \mu \mathrm{g} / \mathrm{mL}$ against $\mathrm{S}$. aureus ATCC 33591 (Table 2).

MIC assay was carried to determine if the the lose dose PVP-I test article had anti-fungal activity. At serially diluted concentrations as low as $6.25 \%$ and $3.125 \%$, PVP-I solutions showed anti-fungal activity against all the test strains. Fluconazole was ineffective against $C$. albicans, A. fumigatus and C. auris. Amphotericin B had good anti-fungal activity against all the strains tested (Table 3 ).

\section{Discussion}

Povidone-iodine is one of the few topical antimicrobials shown to be effective against bacteria, viruses, fungi, spores, protozoa, and amoebic cysts [16]. In PVP-I solutions, iodine forms a complex with the synthetic carrier polymer polyvinypyrrolidone, which itself has no microbiocidal activity [17]. In an aqueous medium, free iodine is released into solution from the povidoneiodine complex and equilibrium is established, with more free iodine being released from the povidone-iodine reservoir as iodine-consuming germicidal activity proceeds $[18,19]$. As surgical antiseptics for routine medical practice, PVP-I products are supplied as $5 \%(\mathrm{w} / \mathrm{w})$ or $10 \%(\mathrm{w} / \mathrm{w})$ solutions, however in vitro analysis paradoxically suggests that solutions with a lower concentration may be more effective than those with higher concentrations [20]. This unique PVP-I chemistry allowed efficacy testing at extremely low concentrations in this study, 
Table 3: MIC testing results

\begin{tabular}{|c|c|c|c|c|c|c|c|c|}
\hline \multirow{3}{*}{$\begin{array}{l}\text { Strains } \\
\text { C. albicans } \\
\end{array}$} & \multirow{3}{*}{$\begin{array}{c}\text { Isolate ID } \\
\text { ATCC } 90028 \\
\end{array}$} & \multirow{3}{*}{$\begin{array}{c}\text { Phenotype } \\
\text { QC }\end{array}$} & \multicolumn{6}{|c|}{ MIC (\% PVP-I and $\mu \mathrm{g} / \mathrm{mL}$ Antifungal) } \\
\hline & & & \multicolumn{2}{|c|}{ 1\% PVP-I Solution } & \multicolumn{2}{|c|}{ Amphotericin B } & \multicolumn{2}{|c|}{ Fluconazole } \\
\hline & & & 6.25 & 6.25 & 0.5 & 0.5 & $>64$ & $>64$ \\
\hline A. fumigatus & ATCC MYA 3626 & QC & 6.25 & 6.25 & 1 & 1 & $>64$ & $>64$ \\
\hline M. canis & ATCC 36299 & QC & 3.125 & 3.125 & 0.125 & 0.125 & 8 & 8 \\
\hline T. mentagrophytes & ATCC MYA 4439 & QC & 3.125 & 3.125 & 0.25 & 0.25 & 16 & 16 \\
\hline C. auris & CDC 0389 & QC & 3.125 & 3.125 & 2 & 2 & $>64$ & $>64$ \\
\hline
\end{tabular}

which yielded complete eradication of all tested biofilm-forming microorganisms. At serially diluted concentrations as low as $6.25 \%$ and $3.125 \%$, PVP-I solutions showed anti-fungal activity against all the test strains. In contrast to other antiseptics (with the apparent exception of an absence of cross-resistance to silver), no acquired resistance or cross-resistance has been reported for molecular iodine in over 150 years of use [21].

Biofilms are found in approximately $60 \%$ of chronic wounds and $6 \%$ of acute wounds. Eradication of the resident bacteria is an ongoing challenge in the treatment of these cases. Effective antiseptics for wound healing should ideally address both inflammation and biofilm formation associated with chronic wounds [22]. In vitro evidence suggests that iodine not only has broad spectrum antibacterial effects, but also counteracts inflammation elicited by both pathogens and the host response. These anti-inflammatory effects appear to be multifactorial and have been shown to be clinically relevant [23]. Antiseptics, as an alternative for topical wound treatment, tend to be microbiocidal and have a broader spectrum of antimicrobial activity than antibiotics. Furthermore, in comparison to most antibiotics and antifungals, antiseptics reduce the likelihood of resistance emerging due to their multiple mechanisms of action targeting various aspects of cell biology in microbes; hence the use of topical antibiotics and antifungals should be discouraged if appropriate antiseptics are available [24]. Although amphotericin $\mathrm{B}$ was effective against all fungal strains, and the other control antibiotics and antifungals in this study were partially effective, they all share to propensity for this development of resistance as none are broad spectrum antimicrobials, nor are they produced in topical formulations. Comparison of the antimicrobial spectra of the most commonly used antiseptics (Povidone-iodine 10\%, Polihexanide, Chlorhexidine, Octenidine, Ethanol 70\%) against Gram-positive, Gram-negative, Actinobacteria, spores, fungi and viruses demonstrates the strong microbiocidal activity of Povidone-Iodine $10 \%$ against all classes of microorganisms. The remaining categories of antiseptics were not strongly biocidal across all categories [24].

The use of PVP-I for chronic wounds has been well documented in the literature. In vivo human studies conducted in varying settings have established the efficacy of PVP-I in reducing the bacterial load in both acute and chronic wounds [25-31]. There have been concerns about perceived cytotoxicity with PVP-I, and the potential detrimental effect of PVP-I on wound healing, and therefore biofilms, has been widely argued, with several in vitro studies demonstrating the dose-dependent cytotoxicity of PVP-I on cultures of granulocytes, monocytes, keratinocytes, and fibroblasts [32-34]. In vivo studies have failed to demonstrate detrimental effects on wound healing and the much lower concentrations of PVP-I used in this study reduce this potential effect greatly. Low dose PVP-I formulations for a variety of diseases have recently gained interest in the eye, ear and skin without any reported toxicity $[11,12,35]$.

Also of note is the efficacy of low dose PVP-I against a biofilm comprised of C. auris, which has proven to be multi-drug resistant and difficult to culture emerging pathogen which can be causative in both systemic and wound infections. To our knowledge, this is the first topical approach to $\mathrm{C}$. auris. The limitations of this study include utilization of the MIC assay for fungal organisms, rather than the MBEC assay. The MBEC is a more comprehensive test and better simulator of in vivo biofilm conditions; however this assay is not currently developed for fungi as they are much less prevalent as causative agents for biofilms. Another limitation is the study performed was in vitro and may not mimic in vivo conditions.

\section{Conclusion}

Established biofilms of multi-drug resistant $S$. aureus, $P$. aeruginosa, $K$. pneumoniae and $C$. albicans can be successfully disrupted in vitro by treatment with a dilute PVP-I solution or gel. Concentrations as low as $6.25 \%$ and $3.125 \%$ PVP-I serially diluted solutions showed anti-fungal activity against Candida auris, Trichophton mentagrophytes, Microsporum canis, Candida albicans and Aspergillus fumigatus strains in the MIC assay. As the search for potent, non-toxic anti-biofilm agents continues to evolve, further investigation of dilute PVP-I-containing systems in vitro and in vivo could yield a new class of therapeutic agents with important efficacy for recalcitrant, chronic wounds.

\section{Declarations}

Conflict of Interest: All authors listed are employees and equity holders in Veloce BioPharma.

\section{References}

1. Otto M. Staphylococcal infections: mechanisms of biofilm maturation and detachment as critical determinants of pathogenicity. Annu Rev Med. 2013;64:175-188. doi: 10.1146/annurev-med-042711-140023

2. Jamal M, Ahmad W, Andleeb S, Jalil F, Imran M, Nawaz MA, et al. Bacterial biofilm and associated infections. J Chin Med Assoc. 2018;81(1):7-11. doi: 10.1016/j.jcma.2017.07.012 
3. Zacchino SA, Butassi E, Cordisco E, Svetaz LA. Hybrid combinations containing natural products and antimicrobial drugs that interfere with bacterial and fungal biofilms. Phytomedicine. 2017;37:14-26. doi: 10.1016/j.phymed.2017.10.021

4. Joo HS, Otto M. Mechanisms of resistance to antimicrobial peptides in staphylococci. Biochim Biophys Acta. 2015;1848(11 Pt B):3055-3061. doi: 10.1016/j.bbamem.2015.02.009

5. Vuong, C, Voyich JM, Fischer ER, Braughton KR, Whitney AR, DeLeo FR, et al. Polysaccharide intercellular adhesin (PIA) protects Staphylococcus epidermidis against major components of the human innate immune system. Cell Microbiol. 2004;6(3):269-275.

6. Davis SC, Ricotti C, Cazzaniga A, Welsh E, Eaglstein WH, Mertz PM. Microscopic and physiologic evidence for biofilm-associated wound colonization in vivo. Wound Repair Regen. 2008;16(1):23-29. doi: 10.1111/j.1524-475X.2007.00303.x

7. Takeo M, Lee W, Ito M. Wound healing and skin regeneration. Cold Spring Harb Perspect Med. 2015;5(1):a023267-a023267. doi: 10.1101/cshperspect.a023267

8. Coletti D, Teodori L, Lin Z, Beranudin JF, Adamo S. Restoration versus reconstruction: cellular mechanisms of skin, nerve and muscle regeneration compared. Regen Med Res. 2013;1(1):4. doi: 10.1186/2050-490X-1-4

9. Swanson T, Angel D, Sussman G, Cooper R, Haesler E, Ousey K, et al. Wound infection in clinical practice: principles of best practice. Wounds International 2016. 2016.

10. Omar A, Wright JB, Schultz G, Burrell R, Nadworthy P. Microbial Biofilms and Chronic Wounds. Microorganisms. 2017;5(1): pii: E9. doi: 10.3390/microorganisms5010009

11.Capriotti K, Stewart KP, Pelletier JS, Capriotti JA. Molluscum Contagiosum treated With Dilute Povidone-iodine: A Series of Cases. J Clin Aesth Derm. 2017;10(3):41-45.

12. Pelletier JS, Stewart KP, Capriotti K, Capriotti JA. Rosacea Blepharitis Treated with A Novel Preparation of Dilute Povidone-Iodine and Dimethylsulfoxide: A Case Report and Review of the Literature. Ophthalm Ther. 2015;4:143-150. doi: 10.1007/s40123-015-0040-4

13. Clinical and Laboratory Standards Institute (CLSI). Reference method for broth dilution antifungal susceptibility testing of filamentous fungi: approved standard-Second Edition CLSI document M38-A2. 2008.

14. Clinical and Laboratory Standards Institute (CLSI). Reference Method for Broth Dilution Antifungal Susceptibility Testing of Yeasts; Approved Standard-Third Edition. CLSI document M27-A3. 2008.

15.Ceri H, Olson M, Morck D, Storey D, Read R, Buret A, Olson B. The MBEC Assay System: multiple equivalent biofilms for antibiotic and biocide susceptibility testing. Methods Enzymol. 2001;337:377-385

16.Jayaraja Kumar K, Jayachandran E, Hemanth Kumar Reddy C, Gunashakaran V, Ramesh Y, Kalayan Babu P, et al. Application of broad spectrum antiseptic povidone iodine as powerful action: a review. J Pharm Sci Technol. 2009;1(2):48-58.

17.Ripa S, Bruno R, Reder R. Clinical applications of Povidone-Iodine as a topical antimicrobial. Handbook of Topical Antimicrobials Industrial Applications, Industrial applications in consumer products and Pharmaceuticals: CRC Press, 2002. 2002.
18. Fleischer W, Reimer K. Povidone-iodine in antisepsis state of the art. Dermatology. 1997;195 Suppl 2:3-9.

19. Rackur H. New aspects of mechanism of action of povidone-iodine. J Hosp Infect. 1985;6 Suppl A:13-23.

20. Berkelman RL, Holland BW, Anderson RL. Increased Bactericidal Activity of Dilute Preparations of Povidone-Iodine Solutions. J Clin Microbiol. 1982;15(4):635-639.

21.European Wound Management Association (EWMA). Position Document: Management of Wound Infection. 2006.

22.Leaper DJ, Schultz G, Carville K, Fletcher J, Swanson T, Drake R. Extending the TIME concept: what have we learned in the past 10 years? (*). Int Wound J. 2012;9 Suppl 2:1-19. doi: 10.1111/j.1742481X.2012.01097.x

23. Bigliardi PL, Alsagoff SA, El-Kafrawi HY, Pyon JK, Wa CT, Villa MA. Povidone iodine in wound healing: A review of current concepts andpractices. Int J Surg. 2017;44:260-268. doi: 10.1016/j. ijsu.2017.06.073

24. Babu PA, Kumar PS, Padmaja P, Roa TK, Chitti S. MIC database: A collection of antimicrobial compounds from literature. Bioinformation. 2009;4(2):75-77.

25. Fumal I, Braham C, Paquet P, Piérard- Franchimont C, Piérard GE. The beneficial toxicity paradox of antimicrobials in leg ulcer healing impaired by a polymicrobial flora: a proof-of-concept study. Dermatology. 2002;204 Suppl 1:70-74.

26. Daróczy J. Antiseptic efficacy of local disinfecting povidone-iodine (Betadine) therapy in chronic wounds of lymphedematous patients. Dermatology. 2002;204 Suppl 1:75-78.

27. Woo KY. Management of non-healable or maintenance wounds with topical povidone iodine. Int Wound J. 2014;11(6):622-626. doi: 10.1111/iwj.12017

28. Han KH, Maitra AK. Management of partial skin thickness burn wounds with Iodine dressings. Burns. 1989;15(6):399-402.

29. Homann HH, Rosbach O, Moll W, Vogt PM, Germann G, Hopp M, et al. A liposome hydrogel with polyvinyl-pyrrolidone iodine in the local treatment of partial-thickness burn wounds. Ann Plast Surg. 2007;59(4):423-427.

30. Vogt PM, Hauser J, Rossbach O, Bosse B, Fleischer W, Steinau HU, et al. Polyvinyl pyr- rolidone-iodine liposome hydrogel improves epithelialization by combining moisture and antisepsis: a new concept in wound therapy. Wound Repair Regen. 2001;9(2):116-122.

31. Vogt PM, Reimer K, Hauser J, Rossbach O, Steinau HU, Bosse B, et al. PVP-iodine in hydro- somes and hydrogel-A novel concept in wound therapy leads to enhanced epithelialization and reduced loss of skin grafts. Burns. 2006;32(6):698-705.

32. Lineaweaver W, Howard R, Soucy D, McMorris S, Freeman J, Crain C, et al. Topical antimicrobial toxicity. Arch Surg. 1985;120(3):267-270.

33. Burks RI. Povidone-iodine solution in wound treatment. Phys Ther. 1998;78(2):212-218.

34. Van den Broek PJ, Buys LF, Van Furth R. Interaction of povidone-iodine compounds, phagocytic cells, and microorganisms. Anti-microb Agents Chemother. 1982;22(4):593-597.

35. Tessema B, Wycherly B, Arumugam S, Capriotti K, Pelletier J, Barone S, Capriotti J. Efficacy of Dilute Povidone-Iodine Preparations Against Multi-Drug Resistant Biofilms of Staphylococcus aureus, Klebsiella pneumoniae, Pseudomonas aeruginosa and Candida albicans. Indian Jour of Research. 2018;7(1):376-377. 